\title{
Helping Students with Attention Deficit Hyperactivity Disorder Succeed in the Classroom
}

\author{
Marjorie Montague and Cynthia Warger
}

Agree or disagree?

- Attention deficit hyperactivity disorder (ADHD) is just the politically correct way these days to refer to kids with learning disabilities.

- Kids grow out of the characteristics associated with ADHD.

- ADHD can be cured with drugs.

- You always can spot kids who are faking ADHD; although they have trouble doing any schoolwork, they have no problem watching television. ADHD can be prevented by keeping kids away from candy and junk food.

Most of you have heard these statements, or variations of them, before. Even though all of the statements are false, they represent a common body of misinformation about ADHD. Myths about ADHD - what it is, what it is not, its etiology, its treatment, and its prognosisabound in the field. Because ADHD is a relatively new area of study, inaccuracies and halftruths are to be expected. Nonetheless, once a student with ADHD becomes a member of your classroom - which is increasingly becoming the case-teachers must learn as much as they can about what that student needs to be successful.

Over the last few years we have learned much about serving the educational needs of students with ADHD. This article is intended to provide teachers and special service providers with basic information about ADHD related to diagnosis and classroom practice. Strategies that have proven promising in helping students with ADHD achieve positive academic results will also be presented. In addition, because students with ADHD often require the services of several professionals, a brief overview of the role of collaboration is included.

As you read through the information, keep in mind that the field of ADHD is emerging. Although we do know quite a lot, our knowledge base has gaps. For example, no agreement has been reached regarding the "best" treatment. We do not know why sometimes strategies work with one child only to fail with another. What we do know, however, is that many of the instructional strategies that support students with ADHD also enhance the learning of all students.

Marjorie Montague is with the University of Miami, and Cynthia Warger with Warger, Eavy, \& Associates, Reston, Virginia. 


\section{WHAT WE KNOW ABOUT ADHD}

A number of characteristics are associated with ADHD.

- Inattention. A child with ADHD has difficulty sustaining attention when effort is required. Attentional problems fluctuate and frequently depend on the situation. Children with ADHD have been described as having an attentional bias toward novelty because they seem to need more stimulation and variety than other children.

- Distractibility. Students with ADHD usually have difficulty staying on task. They are easily distracted, appear not to listen, and seldom finish their work without close supervision.

- Impulse control. Hand-in-hand with distractibility is impulsivity. Students with ADHD commonly blurt out an-

\section{Focuson Exceptional children}

ISSN $0015-511 \mathrm{X}$ FOCUS ON EXCEPTIONAL CHILDREN (USPS 203-360) is published monthly except June, July, and August as a service to teachers, special educators, curriculum specialists, administrators, and those concerned with the special education of exceptional children. This publication is annotated and indexed by the ERIC Clearinghouse on Handicapped and Gifted Children for publication in the monthly Current Index to Joumals in Education (CUE) and the quarterly index, Exceptional Children Education Resources (ECER). The full text of Focus on Exceptional Children is also available in the electronic versions of the Education Index. It is also available in microfilm from Xerox University Microtilms, Ann Arbor, MI. Subscription rates: Individual, $\$ 30$ per year: institutions, \$40 per year. Copyright 1 1997. Love Publishing Company. All rights reserved. Reproduction in whole or part without written permission is prohibited. Printed in the United States of America. Periodicals postage is paid at Denver, Colorado. POSTMASTER: Send address changes to:

$$
\begin{gathered}
\text { Love Publishing Company } \\
\text { Executive and Editorial Office } \\
\text { P.O. Box } 22353 \\
\text { Denver, Colorado } 80222 \\
\text { Telephone (303) } 757-2579
\end{gathered}
$$

Edward L. Meyen

University of Kansas

Richard J. Whelan

University of Kansas Medical Center
Stanley F. Love

Publisher
Glenn A. Vergason Georgia State University

Thomas Love Associate Editor swers before questions have been completed, have difficulty taking turns, and interrupt when others are speaking.

- Overactivity. High levels of hyperactivity frequently are present with this disorder. Students may make noises at inappropriate times, leave their seats repeatedly without permission, and talk out during quiet time.

Some students with ADHD display behavioral or social problems in the school setting. They may be noncompliant in response to teacher directions, behave aggressively toward peers, and destroy property in response to the answer "no." Consider the following examples.

During a 20-minute independent seatwork assignment, second-grade teacher Mr. Webber told Sandra on three different occasions to return to her seat. Each time, Sandra responded to the command with tantrum behaviors, including stomping her foot, crying, tearing up papers, and running out the door. Her off-task behaviors continued into the next lesson, when she refused to join the reading group. Halfway through the lesson, Sandra came and sat with the group; instead of participating, however, she sucked her thumb and looked around the room. When it came time for Mr. Webber to dispense group rewards (stars on the students' assignment sheets) for the reading task, Sandra shoved her way to the front and began screaming "me first!" Mr. Webber ignored Sandra and passed out stars to the other students. Grabbing another student's sheet and ripping it to shreds, Sandra screamed that she hated Mr. Webber and began to cry.

$$
* * *
$$

For the second time this week, 10-year-old Derrick has been late to school. When Ms. Murray asked him why, he responded that he was swinging on the playground. She then asked him for his field trip permission slip, and he responded with a blank stare. "Did you forget it?" Ms. Murray asked. Derrick nodded his head affirmatively. Ms. Murray directed him to go to his seat and get ready for math. On his way, Derrick stopped at the aquarium and watched the fish for several minutes. He then proceeded to get a drink of water and look at the plants on the window sill.

Derrick had just started to play with the Venetian blinds cord when Ms. Murray noticed him. "Derrick, you are supposed to be in your seat, now." Derrick looked up and ran to his seat. He did not watch where he was going and tripped over a student's book bag. As Derrick scrambled around on the floor, several children started laughing. Derrick responded with a quacking noise as he crawled to his seat. 
Although many students have characteristics and behaviors that interfere with their learning, children like Sandra and Derrick seem to have problems that may require a more careful look. Even though no two children have the same set of characteristics or behaviors, ADHD has been defined clearly in American Psychiatric Association's Diagnostic and Statistical Manual of Mental Disorders (DSM-IV; APA, 1994) as follows:

\begin{abstract}
Primary characteristics of ADHD are inattention, hyperactivity, and impulsivity. For diagnosis of ADD, not only must students display the symptoms associated with the primary characteristics, but they also must meet the following criteria regarding persistence, time of onset, pervasiveness, and severity. That is, first, an individual must have exhibited either symptoms of inattention and/or hyperactivity-impulsivity as listed in DSM-IV for a period of at least six months to a degree that is developmentally inappropriate. Second, an individual must have displayed these symptoms prior to seven years of age. Third, the symptoms must be present in two or more situations (e.g., school, home, work, etc.). Fourth, the symptoms presented must be serious enough to cause clinically significant distress or impairment in social, academic, or occupational functioning.
\end{abstract}

Currently, educational psychologists use this definition in determining the presence of the condition in children who are referred by their teachers or parents. An estimated 3\% to $5 \%$ of school-aged children have ADHD. For some children, the behaviors symptomatic of ADHD may seem to improve in adolescence. ADHD, however, is a lifelong condition manifested in different ways during the developmental periods.

Complicating our understanding, as well as treatment, of the disorder is that its causes presently are unknown. Research investigations are being directed at several possibilities, including:

- Heredity or genetic causes.

- Prenatal alcohol and drug exposure.

- Lead poisoning.

- Biological or physiological conditions.

- Complications or trauma during birth.

The causal relationship of food allergies to ADHD has been promoted in the non-research-based literature. Many professionals believe such a relationship exists. Research to date, however, has not consistently demonstrated any linkage.

\section{IDENTIFYING CHILDREN FOR POSSIBLE REFERRAL}

All youngsters exhibit behaviors associated with ADHD to some degree in certain situations. Thus, identifying a student as having ADHD requires a multifaceted diagnosis and evaluation process. Comprehensive assessment of children with ADHD for educational purposes is a multistage, multimodal process that gathers data and information to make decisions about the nature of children's educational problems, their need for specialized programs and services, and the efficacy of the programs and services they receive.

The foundation for effective implementation of this approach to assessment is the multidisciplinary team, consisting of general and special educators, administrators, and related service personnel such as school psychologists, nurses, or speech and language clinicians, as well as parents and students. All of the team members should be involved in making decisions about assessment and identification of students who have problems that may be associated with ADHD.

A comprehensive assessment of ADHD for educational purposes should focus on the following:

- Primary characteristics

- Co-occurring disabilities

- Severity of ADHD

- Duration of symptoms

- Situational and temporal variability

- Educational characteristics and needs

- Social adjustment

The process of assessment and identification of youngsters with ADHD is done at three levels.

1. At the first level, children are screened, referred, if appropriate, and then evaluated individually for symptoms or characteristics that may be associated with ADHD. Instruments and procedures include behavior rating scales, checklists, interviews, and direct observations. Information at this level is used to determine the presence or absence of ADHD.

2. Children with ADHD who have been identified as needing specialized educational programs are assessed further to pinpoint their strengths and educational needs in academic, behavioral, and social-emotional domains. Information from this level is used to design either an individualized education program as required by the Individuals with Disabilities Education Act (IDEA) for students with ADHD who are served in special education programs or an Accommodation Plan as required by 
Section 504 of the Vocational Rehabilitation Act of 1973 for students with ADHD who are served in general education classes.

3. Effectiveness of the educational program is evaluated and information from this level is used to modify the educational program with respect to instruction, classroom management, and organization of the learning environment.

A comprehensive assessment of ADHD for educational purposes should have the following components (McKinney, Montague, and Hocutt, 1993).

1. Assess the primary characteristics (attention, impulsivity, and hyperactivity) of $A D H D$. The relative severity of the ADHD symptoms of inattention, impulsivity, and hyperactivity can vary among children and each symptom may impair students' academic performance and social-emotional functioning in different ways. Therefore, all three constructs must be measured.

2. Assess co-occurring disabilities. Because of relatively high rates of co-occurrence of ADHD with other disabilities, assessing for a co-occurring problem when a student is suspected of having ADHD is entirely reasonable. Students with ADHD and a co-occurring problem are likely to have more serious problems and outcomes than students who have ADHD alone. ADHD can co-occur with learning disabilities (LD) in at least $10 \%$ to $20 \%$ of cases when stringent identification criteria are applied for both conditions, although the prevalence of co-occurrence varies from $9 \%$ to $63 \%$ across studies (McKinney et al., 1993).

Similarly, researchers have reported consistently higher rates of co-occurrence between ADHD and disruptive behavior disorders marked by aggression, oppositional-defiant behavior, and conduct problems. The evidence for the presence of co-occurring emotional problems is less consistent but becomes significant for girls with ADHD as they approach adolescence. Therefore, if a student is suspected of having ADHD, it is reasonable to expect that the student also may have co-occurring LD or emotional/behavioral disorders (EBD). Thus, appropriate instruments should be used to include or exclude the presence of these problems as part of a comprehensive assessment strategy.

3. Assess the severity of $A D H D$. Instruments keyed specifically to DSM criteria (rather than to the underlying constructs of ADHD) can be used to assess the severity of $\mathrm{ADHD}$ in terms of the number of symptoms that ex- ceed the required threshold for any one subtype. In addition, multi-factor instruments not keyed to DSM criteria can be used not only to confirm a DSM diagnosis but also to support assessment of severity. In general, to determine severity, two standard deviations below the mean can be used as a criterion for most instruments.

4. Assess the duration of symptoms. ADHD is a pervasive disorder that appears early in childhood and persists into adult life. The preschool literature suggests that ADHD with hyperactivity as the major symptom, along with aggressive or oppositional behavior, can be identified as early as 3 years, and these symptoms persist reliably in a significant number of cases well into the elementary grades (Campbell \& Ewing, 1990). Attentional problems (ADHD without hyperactivity) are less visible than activity and impulse-control problems and teachers typically recognize these during the primary grades.

DSM-IV (APA, 1994) included the previous DSM criteria that ADHD symptoms must be evident before 7 years of age and must persist for at least 6 months. The collection of parent and teacher interview data, along with a thorough review of school records and treatment history, is important with respect to these criteria.

5. Assess situational and temporal variability. An important consideration in assessing ADHD is that evidence of pervasiveness is needed to show that inattention, impulsiveness, and hyperactivity are not specific to certain situations (e.g., displayed in school but not at home, or only in some school or home situations). As noted previously, two assessment strategies can address this problem. First, instruments are available for collecting ratings of severity of ADHD symptoms in different school and home situations (DuPaul \& Barkley, 1992). Evidence is lacking, however, on the effects of ADHD symptoms on the performance of specific instructional activities and in different instructional contexts. The second strategy - the use of observational instruments for assessing ADHD symptoms and, more generally, on- and off-task behavior-is helpful in measuring academic performance, as well as in planning and monitoring the effectiveness of instructional and behavioral accommodations.

6. Assess educational characteristics and needs. For educational purposes we have to go beyond the ADHD literature (which is primarily clinical in orientation) and apply currently used methods for assessing educational/instructional needs (e.g., measures of on- or off- 
task behavior, criterion-referenced tests). The purpose of this type of assessment is to identify students with ADHD who need general educational accommodations or perhaps special education and also to aid in planning and monitoring each child's educational program.

A common finding across studies in the assessment literature on ADHD is that students with ADHD tend to score below normal comparison samples on IQ and achievement tests but frequently still within the normal range (McKinney et al., 1993). Although the symptoms of ADHD may impair test performance, many studies failed to control variables, such as socioeconomic status, and to account for co-occurring conditions. When children with co-occurring LD and problem behaviors were compared separately to those with only ADHD in well defined samples, evidence to suggest impaired ability and achievement was lacking (e.g., see Dykman \& Ackerman, 1991). At the same time, functional outcomes for children with ADHD in follow-up studies have been poor with respect to frequency of retention, suspension, and dropout rates (Barkley, Fischer, Edelbrock, \& Smallish, 1990). Although these outcomes apply mainly to clinic-identified hyperactive students, some evidence suggests that children with ADHD may become more handicapped educationally in the long term because of its association with LD and EBD and the effects of continued school failure. In any event, the problem remains to better specify the educational characteristics of students with ADHD without the complications imposed by other co-existing conditions.

In this regard, some have argued that children with ADHD display difficulties in academic productivity, as assessed by work completion, on-task behavior, and accuracy of responding on academic tasks, because of the inability to regulate attention and impulse control (Fowler, Barkley, Reeve, \& Zentall, 1992; Zentall, 1993). Attention and the ability to regulate behavior during task performance have long been known to affect academic performance. Inattention and poor on-task behavior combine with other variables, such as grade-level retention and impulsive cognitive styles, to predict poor academic performance cumulatively over time (McKinney, 1989; McKinney \& Speece, 1986; Osborne, Shulte, \& McKinney, 1991). Evidence of this kind, however, is sparse for the majority of students with ADHD and no other co-occurring disabilities.

Accordingly, we need to go beyond the ADHD literature to apply currently used methods for assessing educational needs and, in particular, instructional needs. One approach that should be considered is using curriculum-based measures to identify students with ADHD who may require general ed- ucation accommodations rather than special education and related services. These measures also could aid in planning and monitoring educational programs.

7. Assess social adjustment. Given consistent findings that most children with ADHD have persistent problems with social relationships, a number of instruments for measuring social competence might be helpful, particularly in terms of developing a given child's educational program.

Placement. The issue of eligibility of students with ADHD under the Individuals with Disabilities Education Act (IDEA) originally was raised in the 101 st Congress during consideration of the Education of the Handicapped Act Amendments of 1990 (PL 101-476). In September 1991, the Department of Education's policy memorandum stated that under certain circumstances a child with ADHD may be eligible for special education and related services under IDEA and clarified the State Education and Local Education Agencies' responsibilities under federal law in serving children with ADHD. Public comments regarding ADHD were reviewed between November 1990 and March 1991 and presented to Congress in May, 1991. Then the U. S. Department of Education developed a policy statement (Davila, Williams, \& MacDonald, 1991) to clarify eligibility for services under IDEA and Section 504 for students with ADHD.

Students with ADHD may qualify for services under the Individuals with Disabilities Education Act (IDEA) or Section 504 if they meet certain criteria. IDEA is a grant statute; Section 504 is a civil rights law. IDEA provides financial assistance to participating states to ensure that students with disabilities receive a free appropriate public education (FAPE) and provides procedural safeguards for these students and their families. The Department of Education, in its policy statement, indicated that a child with ADHD who qualifies for services under IDEA's "other health impaired" category has a "chronic or acute health problem that limits alertness, adversely affects educational performance, and causes a need for special education." A child with ADHD may qualify under other IDEA categories if he or she meets the appropriate identification and placement criteria for another disability category.

Services must be provided to a child with ADHD under Section 504 of the 1973 Vocational Rehabilitation Amendments "if the ADHD substantially limits his or her ability to learn." Section 504 prohibits discrimination against otherwise qualified persons with handicaps in federally assisted programs solely on the basis of the handicap, requires as a con- 
dition of receiving any federal funds that children with disabilities not be denied a free and appropriate public education (FAPE), and mandates procedural safeguards for these students and their families.

Collaborating for appropriate evaluation and instruction. Appropriate evaluation and instruction for students with ADHD depend on how well teachers, parents, and other multidisciplinary team members communicate and cooperate with one another. Teachers often do not know what role they play in referral and evaluation. Parents frequently are reluctant to participate and often do not understand their rights and responsibilities. Other team members, such as the school nurse, the counselor, or the speech and language clinician, may underestimate the importance of their input.

The current trend in education is toward a model that emphasizes collaboration. To meet the needs of students with $\mathrm{ADHD}$, as well as other learning and behavioral problems, teams composed of a variety of individuals must interact and communicate effectively about the student and the student's educational program. The team members can include school administrators, counselors, psychologists, social workers, nurses, speech and language therapists, bilingual education teachers, special education personnel, and other staff in addition to the classroom teacher. The team also should include the parents of the student with ADHD. The team members play different roles in the education of these students.

Teachers or parents usually are the referral agents because they interact with children for extended periods and are able to identify behaviors that cause problems in school and at home. The teacher and parents should communicate regularly and collect anecdotal data about the child before making the referral. Following the referral (usually to the special education department) the teachers and parents are required to complete rating scales and provide relevant information pertaining to the child's behavior. The formal evaluation may take several weeks during which time various types of testing (e.g., vision, hearing, academic, cognitive) and observations (across situations and settings) are completed. Teachers are expected to continue documenting the child's behavior for the duration.

The child may be referred for medical and psychological evaluations, which will help in making appropriate decisions regarding medication and family or individual counseling. Thus, other individuals (e.g., pediatrician, therapist, social worker) may have to be part of the decision-making process

When the evaluation has been completed, the team, which includes the parents, meets to discuss the results and make recommendations regarding placement and program. If the child meets the criteria for ADHD, the team must decide on a special or a general education placement. If the team decides that the child with ADHD qualifies for a special education program, an individualized education program (IEP) is developed. If the team decides otherwise, an accommodation plan must be written. (Development of accommodation plans is described in the last section of this article.) Finally, the child is placed in the appropriate program and the instructional plan, which includes specific curricular and classroom adaptations and accommodations, is initiated.

The teacher continues to document progress and communicate with parents and other service providers such as the school nurse, who may dispense daily medication, or the counselor, who may provide group therapy. School-home collaboration is essential for students with ADHD because these students need ongoing reinforcement for being prepared, organized, and responsible in a variety of contexts. Periodically, the instructional program or plan is reevaluated and revised.

\section{USING YOUR KNOWLEDGE OF ADHD TO ENHANCE LEARNING}

Between $85 \%$ and $90 \%$ of children identified as having ADHD will be served in general education classrooms for part or all of the school day. In most cases, children with ADHD can be educated successfully in a general education program with the help of appropriate school-based interventions. Teachers, working with the child's multidisciplinary team, can plan programs that reflect knowledge about effective practices.

Effective practice for students with ADHD begins with a general understanding about how school requirements might be matched to the students's characteristics. This understanding is derived from functional assessments of children's performance. As teachers gain more specialized knowledge, they will be able to chart the effects of medication on school performance, organize classroom management systems that promote positive behaviors, and select instructional strategies that support academic progress. Through collaboration with other educators, specialists, and concerned individuals, teachers can enhance their ability to design and implement effective educational programs for students with ADHD. Recommendations and strategies for building this knowledge are presented in the following sections, describing how to conduct a functional assessment, monitor medication programs, organize classrooms, manage behavior, and select and implement instructional strategies. 


\section{Conducting a Functional Assessment}

Effective instruction depends on accurate analysis of a student's behavior to target personal-social and academic behaviors that may be interfering with school success. If left unattended, these behaviors may be exacerbated, leading to even more serious behaviors. Functional assessment is a systematic method for understanding and identifying these behaviors, defined here as a "process whereby informed hypothesis statements are developed about relationships between events in the environment and the occurrence of a student's challenging behavior" (Foster-Johnson and Dunlap, 1993). The basic assumptions underlying this approach to assessment are that behavior is related to the context in which it occurs and serves a particular function or purpose for the student, who is gratified in some way (e.g., getting attention, avoiding an unpleasant task) by behaving in a certain way.

Functional assessment provides information on the circumstances surrounding the behavior, the environmental conditions that may be supporting it, the function of the behavior, and the contextual variables that could be maintaining the behavior. When the causal or contributory contextual events are identified and the function of the behavior is determined, the teacher can think about altering the conditions to effect change in behavior or the function of the behavior by forming hypotheses about how these variations may affect the student's target behavior. In this way, intervention plans are developed that focus on specific behaviors and their functional significance.

Functional assessments can be relatively informal or highly systematic. They usually involve direct observations of behavior. The objective of the observations is to collect accurate and sufficiently detailed data that allow the teacher to describe the conditions that influence the targeted behavior. The time periods for observing the behavior and the type of data that would be most useful in describing the behavior are identified (e.g., frequency, duration, magnitude).

To illustrate, Ms. Thorpe, Juan's third-grade teacher, is concerned that Juan leaves his seat frequently and wanders around the classroom. Consequently, he rarely completes his assigned seatwork and often does not seem to know what to do. Ms. Thorpe decides to conduct a functional assessment during the morning reading and language arts period. During this 1 1/2-hour period, students participate in reading group, complete seatwork assignments, and work in centers. In assessing this behavior, Ms. Thorpe decides to focus on the number of times Juan leaves his seat and the length of time he is out of his seat (other than transitions between activities).
She divides the time into 5-minute segments and enlists the aid of a parent volunteer to document the frequency and duration of the behavior during the morning period. The parent observes Juan on two different mornings and records the number of times he leaves his seat, as well as the number of minutes each time. In addition, Ms. Thorpe requests an anecdotal record of his activities during this time. Figure 1 illustrates a simple technique for collecting this type of data.

$$
* * *
$$

When the functional analysis is completed, instructional strategies are developed by articulating desired outcomes for the student. Rather than focusing on problem behaviors, the focus shifts to acceptable and desired behaviors that are realistically within reach for a specific child. In addition, appropriate and effective strategies are based on a functional assessment of a student's behavior with particular regard for the student's intent (Cessna \& Borock, 1993). Thus, the functional significance of the behavior is identified and the outcome behavior considers and reflects the desired outcome from the student's perspective (e.g., attention from peers, teacher attention, avoidance of a math task because the student lacks the skills). When outcome behaviors are identified and coupled with an acceptable (replacement) behavior that will produce the desired outcome (e.g., being positively reinforced for staying on task for 15 minutes during reading group), strategies for attaining that desired outcome can be proposed. Then the conditions can be manipulated to allow the student to learn and practice acceptable behaviors while still attaining desired outcomes.

***

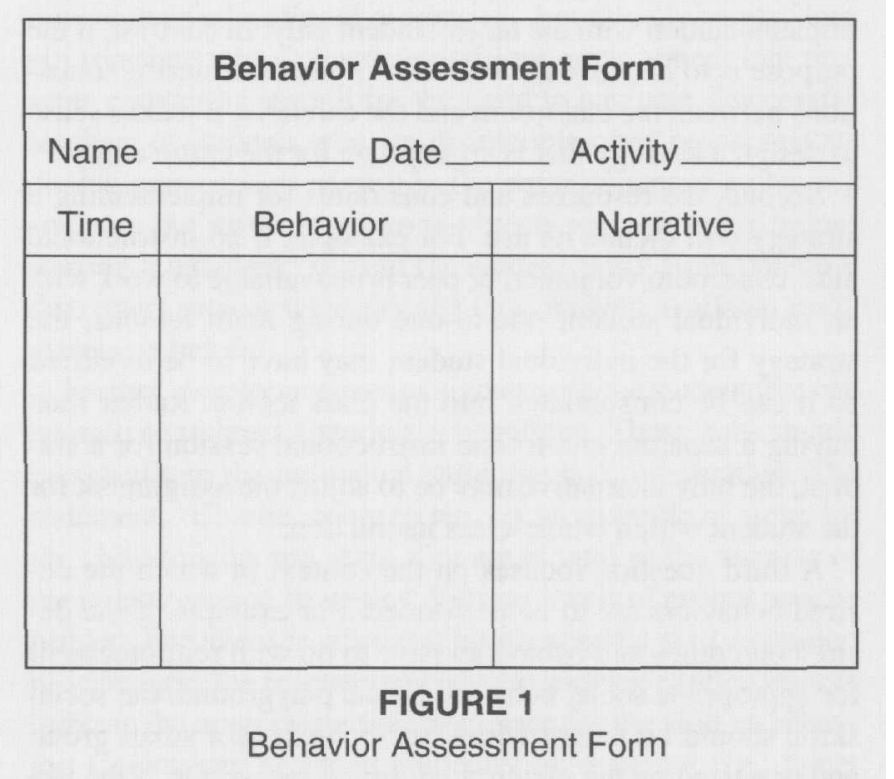


For example, Juan has difficulty staying on task during seatwork. A program should be introduced to reinforce him for staying on task for 2-, then 4-, then 6-minute intervals until his limit is reached, which may be only 8 minutes. Ms. Thorpe thus learns that Juan is able to sustain attention for only 8 successive minutes during seatwork. Understanding this dimension of the student's behavioral pattern enables the teacher to set the conditions so that Juan has a "2-minute break" after 8 minutes and then resumes work for another 8 minutes.

$$
\text { *** }
$$

When educating children with special learning and behavioral needs in heterogeneous classrooms, the dilemma arises of when to choose whole-group methods and when to rely on individualized ones. Several questions should be answered before deciding whether intervention strategies should be implemented with students individually, either singly or within the context of a group, in small groups, or as part of an entire class. These questions have to do with the purpose and goals of instruction, the resources and constraints of implementing it, and the context in which the desired behaviors are to be performed.

The first step addresses the purpose and goals of the instructional strategy. If the purpose is to increase an individual student's on-task behavior during reading group, the strategy may be implemented individually with only that student during group time. If the teacher desires, however, a reinforcement program could be instituted with the entire reading group while maintaining a focus on the target student. Most likely, though, the easiest approach for this example would be implementation with the target student only. In contrast, if the purpose is to improve the behavior of the class during transitions between the classroom and the cafeteria, it makes sense to design a strategy that is appropriate for the entire class.

Second, the resources and constraints for implementing a strategy will dictate its use. For example, if an instructional aide, classroom volunteer, or peer is unavailable to work with an individual student one-to-one during math lessons, the strategy for the individual student may have to be modified so it can be consolidated into the class lesson. Rather than having a separate one-to-one instructional session for a student, the only alternative may be to adjust the assignment for the student within whole-class instruction.

A third question focuses on the context in which the desired behaviors are to be performed. For example, if the desired outcomes and behaviors have to do with reinforcement for appropriate social behavior on the playground, the social skills should be taught within the context of a small group and practiced on the playground during recess. Or, if the tar- get behavior is keeping one's hands to oneself while waiting in the cafeteria line, the strategy could be designed for an individual student and implemented in the cafeteria by enlisting the aid of a cafeteria worker or the supervising teacher.

$$
* * *
$$

Juan's intervention may be nothing more than a simple individualized self-monitoring system. Juan could be taught to set a time clock for 8 minutes at the beginning of seatwork time, give himself a checkmark when the timer sounds, go to the restroom, reset the clock, and then give himself another checkmark when time is up. In this way, he works for 16 minutes on his assignment but with a 2 -minute break in the middle. Incidentally, the assignment should be structured so he can complete it correctly within the allotted time.

$$
* * *
$$

\section{Understanding Medication Programs}

Thanks in part to irresponsible reporting in the press and inaccurate grapevine tips, a large number of citizens hold unfounded beliefs that stimulant medication such as Ritalin cures $\mathrm{ADHD}$ or, at the very least, alone improves the academic and social achievement of children with ADHD. The facts are that in some cases stimulant medication-for practical purposes, stimulant medication refers to a class of drugs that includes the brand names of Dexedrine, Ritalin, and Cylert - when used appropriately can enable children with ADHD to focus their attention and behavior. If a medication program is working, you should expect to see the child become less distractible, more able to concentrate, and more attentive. For children who have associated behavioral difficulties such as aggression and inappropriate social interaction, you also might observe a decrease in disruptive behaviors.

When it is working properly, medication might control certain behaviors that interfere with the child's academic learning and progress. Therefore, although stimulant medication has no effect on academic performance, per se, productivity may improve as a result of controlling the interfering behaviors.

Present estimates suggest that approximately $60 \%$ to $90 \%$ of all students who have been diagnosed as having ADHD will be on a medication program. Thus, you undoubtedly will have children in your classroom who are receiving some type of medical treatment. The choice of medication will depend on the student's symptoms and response to the treatment. Although your role does not include being an adviser to families or physicians regarding medical treatment (the child's parents and physician are responsible for deciding if a medication program is appropriate), as a classroom teacher your under- 
standing of medication programs for children with ADHD is critical to children's learning and their ultimate health. Usually, teachers are responsible for:

- Making sure that students receive their medication on schedule. Most children with ADHD do not remember to take their medication without reminders. Although teachers usually are not responsible for administering medication at school, they are asked to remind students to go to the office (or nurse) for their dosage. These reminders should respect the child's confidentiality. School professionals must administer the medication on time and in the correct dosage and know the student's medication schedule. Otherwise students may have adverse effects, such as aggressive, emotional, or impulsive behavior, as the medication's effects wear off.

- Observing the student's behavior and noting instances that suggest the presence of drug side effects. Side effects might take the form of decreased appetite, insomnia, motor tics, or mood swings. If a possible side effect appears, assistance should be sought from the school nurse, school psychologist, or administrator assigned to the child.

- Documenting student performance indicators that support the use of medication. In some cases the district will have a formal reporting system in place to document progress. At the very least, the child should be monitored and this information shared regularly with the other professionals assigned to child. This documentation includes keeping track of the interfering behaviors, keeping a portfolio of work the child has completed, and watching to see if the interfering behaviors return at certain times of the day or if new inappropriate behaviors emerge.

Classroom teachers need to be aware of medication programs currently in use with the students to ensure the program's integrity, as well as the child's comfort and safety. They must understand the context for using medication so they can support the programs with classroom approaches that maximize student learning. As with most approaches for treating children, medication is only one part of the answer in helping students with ADHD achieve their learning potential. Stimulant medication does not necessarily result in improvement in long-term adjustment in either social behavior or academic achievement (Swanson et al., 1993). Indeed. no empirical evidence has been found for improvements in higher-order skills for children on medication. In effect, medication neither cures the disorder nor enhances academic achievement; rather, it improves the conditions for learning for most children.
Moreover, a decade ago, the American Academy of Pediatrics in 1987 stated that stimulant medication never should be used as the primary treatment for attention deficit behavior. AAP recommended using medication only after other approaches (e.g., behavior modification, classroom management, parent education programs) had been tried and failed to yield positive results, and then in conjunction with those approaches. Regardless of whether the parents and the physician agree upon a medical management plan, the child's learning and behavior problems require schoolbased interventions.

\section{Organizing Classroom Management}

From research we know that a strong classroom management system helps all children develop positive, responsible behavior. Organizing classroom management systems to meet the needs of students with ADHD does not require total revamping. Typical management systems can be enhanced to address the unique characteristics of students with ADHD.

Students with ADHD benefit from structure. At a minimum, an orderly classroom environment that is predictable tends to promote students' success. Clear and concrete rules, expectations, and consequences have to be communicated, and sometimes explicitly taught to these children. In addition, student performance should be monitored daily to sustain motivation and active involvement.

\section{Establishing an Orderly, Predictable Environment}

Students with ADHD need variety, novelty, and stimulation in their educational programs-but this obviously does not translate into a chaotic classroom environment that presents competing stimuli for the child to navigate. Successful teachers of students who are distractible often report that reducing unnecessary stimuli in the environment (e.g.. having students put away extraneous objects and materials before starting a new task, seating the student away from potential distracters such as windows and fans, making available study carrels) is helpful.

Further, developing cues or signals with the student that can be used to redirect attention is beneficial. These cues should be specific to the individual child, the task, or situation. The statement, "Charlie, count to ten," is an example of a cue for the child to stop and relax. Cueing is vital to the success of many intervention strategies. Various levels of cueing may be needed. For instance, after teaching a specific skill, behavior, or technique, the teacher may need to provide explicit cues to indicate the appropriate time and place for the skill or behavior. Cueing can be faded gradually by reducing (i.e., fewer 
cues), changing (e.g., visual and auditory cues to visual cues only), or replacing cues (e.g., external to internal cues). When the behavior becomes automatic, external cues no longer should be necessary. Finally, especially for younger children, teachers may need to define the work space in the classroom. An example might be to pass out carpet squares that the children are to sit on during large group work.

\section{Stating Rules, Expectations, and Consequences Clearly}

Well defined procedures for performing tasks, clearly communicated expectations for student behavior, ongoing positive and corrective feedback, and fair and consistent treatment of students are requisites for good classroom management. Students with ADHD need orderly and organized classrooms where common routines and rules are posted and reviewed as needed. These children need to be taught the conditions and system for rewards and punishments. They also need to be taught how to "regroup" and relax. Teachers need to tell children why they are being praised (e.g., "I can tell you worked hard on those math problems. You have six out of ten correct. Good job. I will help you with the others.") Good teachers also avoid rhetorical questions and sarcasm (e.g., "Why did you do that?"). They strive to create an environment in which all children, including children with ADHD, feel safe and valued.

Students with ADHD typically have difficulty with unstructured activities unless they are taught the steps and procedures specifically. Transitions-either from location to location or from learning task to task - are good examples of activities that present students with challenges. Specific procedures and expected behavior for performing smooth transitions should be communicated clearly to the students. Consider this example.

Allan and Tommy, two students with ADHD in Mr. Levin's first-grade class, were taking Ritalin. Their morning dose began to lose its effect just as the children started to get ready to go to lunch. As a result, the two boys had difficulty getting organized, staying in line, and keeping their hands to themselves while going to lunch. Mr. Levin decided to teach the class "buddy walk," a routine that would help them behave during this transition time.

He developed a cueing system for putting away their materials in an orderly manner and then waiting quietly in their seats for the "buddy walk" cue. Mr. Levin used a bell to cue the students to stop what they were doing and put away their materials. Then he held up a card showing a student with hands folded sitting quietly at a desk. He awarded points to individual children when they were seated with their hands folded. A chart with the children's names was posted, and Mr. Levin gave a point to each child who complied until everyone was seated with their hands folded. He did not say a word until all the children were ready. Then he called the buddies by name to line up at the door.

Allan and Tommy were paired with well behaved children. The buddies held hands and were responsible for each other. Mr. Levin had reviewed with the students the importance of helping and trusting one another. The first buddies to be called were the buddy leaders, who held the door until all the buddy pairs were out. When Allan and Tommy finished lunch, they were excused to go to the office for their afternoon medication. They later joined their buddies on the playground. The class used buddy walk to return to the classroom after playground time.

Understanding consequences also is difficult for students with ADHD who often face punishment without knowing what they did wrong. Identifying the transgression and an alternative, acceptable behavior for children with ADHD is vital in managing their behavior. Mr. Levin implemented a management strategy in his classroom for the entire class. He called the strategy "What should I do next time?" First Mr. Levin led the class in a discussion of "good and bad" classroom behavior. Then he helped them identify the three most important rules for the classroom. They listed the following:

1. Listen to my teacher.

2. Raise my hand when I want to talk.

3. Keep my hands and feet to myself.

In the "What should I do next time?" area, Mr. Levin placed three labeled pictures of children listening to their teacher, raising their hands, and keeping their hands and feet to themselves. He also kept paper, a pencil on a string, and brief assignments to reinforce skills that had been taught. When a child broke a rule, Mr. Levin did the following. He walked over to the child and said in a low voice, "Allan, you broke rule number one. You were not listening to me. Go to the "What should I do next time?" station. Allan knows that he needs to go to the work station, find the correct picture, put his name on a sheet of paper, copy the rule that is written on the picture, and then complete the short assignment (e.g., five addition problems). In this way, children who have difficulty listening, raising their hands before speaking, and keeping their hands off other children learn what they did wrong and what they should do next time. The activity helps to redirect children as they learn alternative behaviors. 


\section{Monitoring and Encouraging Progress}

The benefits of using positive reinforcement in classrooms are well documented (Cameron \& Pierce, 1994). We know that verbal praise and positive feedback enhance students' intrinsic interest in tasks and activities. Moreover, students continue to show intrinsic interest in their work even when the reinforcers are no longer present. Most teachers have a basic understanding of the principles of reinforcement. For reinforcement to work, it must be consistent. Yet, the only thing consistent about students with ADHD is their propensity to require intervention. Difficulty arises when a student's behavior elicits more negative feedback than positive. What to do? The first step is to carefully plan reinforcement programs for students that include incentives and promote successful performance rather than simply completion of a task.

\section{Selecting and Implementing Instructional Strategies}

We might easily assume that if we did everything right, the child would be "cured." This notion can be too overwhelming to some of us to try anything. Or, when our efforts fail, we might adopt the attitude that we were not equipped to do this to begin with. The reality is that we can do a lot of things that will help the child learn to his or her capacity and minimize the negative effects of the ADHD. Classroom strategies do not cure $\mathrm{ADHD}$, but, when applied appropriately, they can improve learning results for kids.

Many checklists are available for modifying instruction to address the special learning needs of students with ADHD (Barkley, 1990; Walker, 1995). Most target the following instructional formats and offer common tips:

- Maintain student involvement in group lessons (e.g., keep objectives clear, teach students cognitive strategies such as "think aloud," deliver the lesson at a brisk pace, prompt for student answers after wait time, model enthusiasm, use meaningful materials, break up presentations with opportunities for students to respond).

- Maintain student involvement in seatwork (e.g., break up long assignments into shorter segments, allow extra time for completing assignments, reduce the number of practice items that students must complete once they have demonstrated mastery).

- Help students engage in learning tasks (e.g., use "to do" lists and checklists, highlight written directions with larger type or color coding, teach students how to use graphic organizers).

In addition, research (Montague, Bergeron, \& LagoDelello, 1997) has identified academic enhancement strate- gies that teachers can use to prevent problems. Two of these procedures that are yielding positive results are self-monitoring and peer tutoring. Another classroom intervention that is also proving promising is social skills instruction.

\section{Self-monitoring}

Teachers can help students who have difficulty getting and staying on task become engaged in and complete academic tasks using a self-monitoring procedure. Self-monitoring is a strategy in which students record some element of their own behavior so they can modify that behavior. This strategy is based on the notion that children can stay on task if they are cued to perform the simple steps and are systematically reinforced for performing the steps. Cues are verbal or nonverbal prompts or signals that trigger specific behaviors. This strategy enables children who have the academic prerequisites to complete the task to monitor themselves as they progress through the assignment.

The self-monitoring strategy may consist of, for example, teacher cues, a student checklist (see Figure 2) and a systematic reinforcement chart. Cues such as the following are designed to help children focus their attention on the task at hand:

- Am I listening to my teacher?

- Do I know what to do?

- Am I finished with my work?

The teacher assists the students who have difficulty staying on-task by giving them verbal and visual cues that correspond to the questions on the checklist. The children monitor their progress and are rewarded with stickers and positive notes to take home when they complete their work.

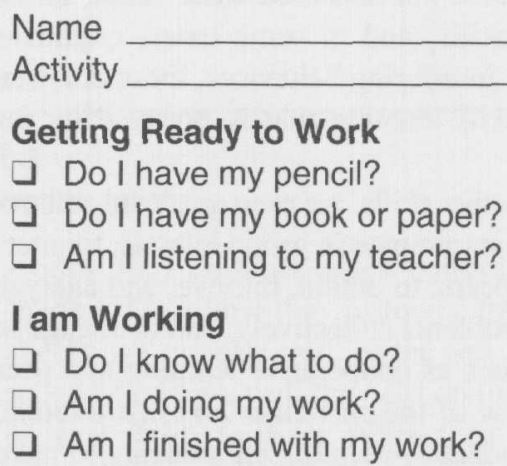

FIGURE 2 Self-Monitoring Checklist. 


\section{Peer Tutoring}

Peer tutoring has been used successfully to improve students' reading and language arts skills. Peer tutoring is an instructional strategy in which students work in pairs as tutor and tutee, or in teams on which team members take turns acting as teacher or tutor for the rest of the group. The goals of peer tutoring are to improve academic learning, develop cooperative work habits, and increase positive social interaction among students.

Peer tutoring takes place when one student who has learned the material helps another student who is working toward mastery. The tutor can be the same age or older than the tutee. In both situations, however, the students must be accepted by and show respect for one another. Often, students need to be instructed in appropriate social skills that will make the tutoring more enjoyable and productive.

Peer tutors are trained in basic instructional procedures and techniques for providing reinforcement and corrective feedback. They also need training in identifying when to ask the teacher for help. The teacher must develop procedures for selecting and matching tutors and tutees and then supervise the tutoring sessions. The teacher essentially orchestrates the peer tutoring program, plans the instruction, and demonstrates the tutoring routine for the student teams. The tutor then works with the learner, providing assistance and feedback.

\section{Social Skills Instruction}

Children with ADHD display many characteristics that put them at risk for learning in most classrooms. We know that all students vary in their physical, psychological, and socialemotional attributes (e.g., cognitive ability, learning style, knowledge base, achievement, motivation, social behavior, and interests). Some teachers have found that, in addition, students with ADHD have not mastered basic social skills, independent working skills, and in some cases, cognitive skills. Because of their interfering behaviors, these children missed out on basic skill learning that is prerequisite for classroom success.

Social skills, among other skills, are prerequisite to achieving academic goals. To participate in group lessons; to interact appropriately with peers; to obtain, retrieve, and analyze information; to solve problems collectively; and to engage in instructional formats such as cooperative learning and peer tutoring - to name a few of the curricular and instructional demands placed on students-requires all students to have mastered basic social skills (Warger \& Rutherford, 1993).
While generally not considered to be part of the standardized curriculum, social skills training, when it is linked directly to the curriculum, often enhances the learning of students with ADHD. These children need explicit instruction in social skills for several reasons.

1. They frequently have attentional problems that interfere with effective communication and social behavior (Javorsky, 1996).

2. They often receive more negative than corrective and positive feedback from adults in school and at home (Campbell, 1990; Lago-Delello, 1996).

3. They typically are poor observational learners, and, therefore, do not attend to environmental cues to the same degree as other children (Hallenbeck \& Kauffman, 1995).

Thus, teachers can ensure that students are not denied access to the curriculum by reviewing their lesson plans and selected instructional formats for prerequisite social skills and then directly teaching those skills (or making accommodations for them). Here's an example:

Ms. Malone is planning a science lab experiment in which her sixth-grade students must work in small groups and share materials. The major prerequisite social skills include listening, following directions, waiting one's turn, asking questions, being responsible to the group for completing the task, saying "please" and "thank you," and sharing. As Ms. Malone reflects on the strengths and needs of her students, she realizes that most students - including Bob, who has ADHDhave not demonstrated the social skill of sharing.

As a result, Ms. Malone decided to link social skills training directly with the science activity. Using an instructional approach to teaching social skills (Warger \& Rutherford, 1996), she first defined "sharing" in concrete, observable terms as follows:

1. Identify that you have something another person might need.

- Think about the task and the tools to complete it.

- Look at your group and decide if they might need the tools.

2. Inform the group that you are willing to share the tools.

- Give conditions (e.g., you can use when I am done).

3. If person asks to use your tool, smile and hand it to that person.

4. If you need to use the tool, smile and ask for it back. 
Evaluation Summary

\begin{tabular}{|c|c|c|c|c|}
\hline \multicolumn{5}{|c|}{ Evaluation Summary } \\
\hline \multicolumn{2}{|c|}{ Child's Name: James } & \multirow{2}{*}{$\begin{array}{c}\text { Age: } 9-0 \\
\begin{array}{c}\text { Prioritize Problem } \\
\text { Behaviors }\end{array}\end{array}$} & \multirow{2}{*}{$\begin{array}{l}\text { Grade: } 3.1 \\
\text { Ideal Outcomes }\end{array}$} & \multirow{2}{*}{$\begin{array}{l}\text { Date: September 15, } 1997 \\
\text { Recommendations for } \\
\text { Functional Analysis }\end{array}$} \\
\hline Domain & Characteristics & & & \\
\hline Academic & $\begin{array}{l}\text { Strengths: } \\
\text { _Verbal skills } \\
\text { _Math calculation } \\
\text { Weaknesses: } \\
\text { _Visual perceptual speed } \\
\text { _Reading } \\
\text { _Spelling/writing } \\
\text { _Visual/spatial processes }\end{array}$ & $\begin{array}{l}\text { 1. Reading (decoding, } \\
\text { word recognition) } \\
\text { 2. Writing } \\
\text { 3. Visual-motor tasks }\end{array}$ & $\begin{array}{l}\text { 1. Read at or above } \\
\text { grade level } \\
\text { 2. Write fluently }\end{array}$ & $\begin{array}{l}\text { Informal reading } \\
\quad \text { inventory } \\
\text { Writing samples } \\
\text { Portfolio assessment }\end{array}$ \\
\hline Behavioral & $\begin{array}{l}\text { Strengths: } \\
\text { _On task } 75 \% \text { time if } \\
\text { task is at his level } \\
\text { Weaknesses: } \\
\text { _Attention/frustration } \\
\text { _Out-of-seat behavior }\end{array}$ & $\begin{array}{l}\text { 1. Attention } \\
\text { 2. Distractibility } \\
\text { 3. Hyperactivity } \\
\text { 4. Impulsivity }\end{array}$ & $\begin{array}{l}\text { 1. } 85 \% \text { to } 100 \% \\
\text { on-task behavior } \\
\text { 2. } 85 \% \text { to } 100 \% \\
\text { in-seat behavior } \\
\text { 3. } 85 \% \text { to } 100 \% \\
\text { attention span }\end{array}$ & $\begin{array}{l}\text { Systematic observations } \\
\text { Parent interviews }\end{array}$ \\
\hline Social & $\begin{array}{l}\text { Strengths: } \\
\text { _Shows respect } \\
\text { _Good attitude } \\
\text { Weaknesses: } \\
\text { _Easily led } \\
\text { _Withdrawn } \\
\text { _Aggressive at times }\end{array}$ & $\begin{array}{l}\text { 1. Social/ } \\
\text { communication skills } \\
\text { 2. Peer interactions }\end{array}$ & $\begin{array}{l}\text { 1. Age-appropriate } \\
\text { social adjustment }\end{array}$ & $\begin{array}{l}\text { Observations of social } \\
\text { interactions with } \\
\text { peers and adults } \\
\text { Teacher and parent } \\
\text { rating scales }\end{array}$ \\
\hline Emotional & $\begin{array}{l}\text { Strengths: } \\
\text { _Manages anger } \\
\text { Weaknesses: } \\
\text { _Anxiety } \\
\text { _Excessive need for praise } \\
\text { _Low self-esteem } \\
\text { _Hides feelings }\end{array}$ & $\begin{array}{l}\text { 1. Self-esteem } \\
\text { 2. Self-concept } \\
\text { 3. Self-confidence }\end{array}$ & $\begin{array}{l}\text { 1. High self-esteem } \\
\text { 2. High self-concept } \\
\text { 3. High self-confidence }\end{array}$ & $\begin{array}{l}\text { Student interviews } \\
\text { Direct observations }\end{array}$ \\
\hline
\end{tabular}

FIGURE 3.

Evaluation Summary for James

Then Ms. Malone made a chart of these steps, which she used in introducing the science activity. She paired her directions for the science activity with the social skills instruction. She articulated the steps for sharing, modeled them, and gave the students a chance to practice. As the students practiced, she gave them specific feedback (or reinforcement) regarding how well they were doing. As the students went into their groups, they each had a self-control card with the steps for sharing. Each time they followed the steps, they recorded a checkmark on their card. At the end of the activity, the group reflected on how well they did on the experiment, as well as on their ability to share. When seen as part of the classroom curriculum, social skills can support student learning without necessarily needing to be an "add-on." 


\section{PUTTING IT ALL TOGETHER IN THE CLASSROOM}

James is 9 years old and in the third grade. He was referred for a psychoeducational evaluation in the first grade but the child study team recommended waiting until the "child is a little more mature and able to structure his work." He was referred again by his second-grade teacher for an evaluation because of poor academic progress in reading and attentional difficulties.

According to the teacher observation forms completed by his reading teacher and Ms. Hinckley, his second-grade classroom teacher, he had excessive problems staying in his seat, completing his work, staying on task, and making transitions from task to task and room to room. His teachers also indicated that he was highly distractible, overactive, and tense. They noted his short attention span, perseverative behavior patterns, poor motivation, and nervousness.

Ms. Hinckley mentioned that he required a great deal of praise, attention, and encouragement from the teacher to do the simplest tasks. No difficulties with cognitive, perceptual, or motor skills were noted. James' mother commented that he could read and did so fluently but that he often did not complete his chores and homework because of his "forgetfulness." She mentioned that he had been overly active since infancy and never could sit still even long enough to get through a meal without having to get up and walk around.

At the end of second grade, an observation was done by the school psychologist during an arithmetic test. James was observed to stare around the room occasionally but was on task $69 \%$ to $79 \%$ of the time. He stopped once to sharpen his pencil. His speed and accuracy, in comparison to classmates, was normal.

James was evaluated during the summer. During the testing he was somewhat anxious but seemed to cope well until he became frustrated. Then he made self-derogatory comments and complained about the difficulty of the task. Rapport was good, and he talked freely about sports and his family. He worked methodically at times and impulsively at other times.

Results indicated that James scored within the average intellectual range and his strength seemed to be in the verbal rather than the performance measures. His achievement tests indicated slightly below average reading achievement, average math achievement, and below-average spelling and writing achievement. His personality tests revealed tendencies to withdraw from emotionally meaningful relationships with others and from the school environment when he feels unable to cope. His strength resides in being able to respond with effort and cooperation when he feels he is accepted.

The psychologist diagnosed James as having attention deficit hyperactivity disorder, the combined type, based on the information provided by his teachers and mother, as well as the observations and psychoeducational evaluation. That is, he met the following DSM-IV criteria for having both inattention and hyperactivity-impulsivity:

At least six symptoms of inattention persisting for at least 6 months:

- Makes careless mistakes in schoolwork

- Often has difficulty sustaining attention in tasks or play activities

- Often does not seem to listen to what is being said to him

- Often does not follow through on instructions and fails to finish schoolwork or chores

- Often has difficulty organizing tasks and activities

- Is easily distracted by extraneous stimuli

- Is often forgetful in daily activities

At least six symptoms of hyperactivity-impulsivity persisting for at least 6 months:

- Leaves seat in the classroom or in other situations in which remaining seated is expected

- Often has difficulty playing or engaging in leisure activities quietly

- Often fidgets with hands or feet or squirms in seat

- Often acts as if "driven by a motor" and cannot remain still

- Often has difficulty waiting in lines

- Often interrupts or intrudes on others

Evidence that these behaviors were present before the age of 7 .

Evidence that the symptoms are present in two or more situations (home and school).

The disturbance causes significant distress or impairment in academic functioning.

The school psychologist did not recommend placement in special education. The multidisciplinary team met and made the following recommendations:

1. Remain in a general third-grade classroom.

2. Review the results of the psychoeducational evaluation and summarize his functioning across four domains: academic, behavioral, social, and emotional.

3. Based on the information, identify James's strengths and 


\begin{tabular}{|c|c|c|}
\hline \multicolumn{3}{|c|}{ Accommodation Plan } \\
\hline Cnild's Name: James & Age: $9-0$ & Date: september 15, 1997 \\
\hline $\begin{array}{c}\text { Domain } \\
\text { Goals/Objectives }\end{array}$ & Teaching Strategies & Techniques for Monitoring Progress \\
\hline $\begin{array}{l}\text { Academic: } \\
\text { I. Improve reading to } \\
\text { grade level } \\
\text { II. Improve spelling to } \\
\text { grade level }\end{array}$ & $\begin{array}{l}\text { _Use a combination of phonological } \\
\text { programs (e.g., Pals), linguistic readers } \\
\text { (Wright books), and language experience } \\
\text { _Use a modified Fernald approach and } \\
\text { develop a personal word bank } \\
\text { _Use morphographic analysis approach }\end{array}$ & $\begin{array}{l}\text { _Self-recording (graphs and checklists) } \\
\text { _ Read-aloud sessions } \\
\text { __nformal reading inventory }\end{array}$ \\
\hline $\begin{array}{l}\text { Behavioral: } \\
\text { I. Increase on-task } \\
\text { behavior } \\
\text { II. Increase attention } \\
\text { span }\end{array}$ & $\begin{array}{l}\text { Self-monitoring checklist } \\
\text { Positive reinforcement program } \\
\text { _Positive notes home }\end{array}$ & $\begin{array}{l}\text { Academic engaged time } \\
\text { Observations to determine threshold } \\
\text { and increases over time on various } \\
\text { classroom tasks } \\
\text { Monitor productivity level }\end{array}$ \\
\hline $\begin{array}{l}\text { Social: } \\
\text { I. Improve social } \\
\text { adjustment }\end{array}$ & $\begin{array}{l}\text { - Teach specific social skills to practice } \\
\text { in school and at home } \\
\text { _Use cooperative learning groups to } \\
\text { teach small-group skills }\end{array}$ & $\begin{array}{l}\text { _"Homework" and self-evaluation } \\
\text { reports }\end{array}$ \\
\hline $\begin{array}{l}\text { Emotional: } \\
\text { I. Improve self-esteem, } \\
\text { self-concept, and } \\
\text { self-confidence }\end{array}$ & $\begin{array}{l}\text { Positive reinforcement program } \\
\text { emphasizing self-reinforcement }\end{array}$ & _Self-ratings \\
\hline
\end{tabular}

FIGURE 4

Accommodation Plan for James

weaknesses within the domains.

4. Develop an Accommodation Plan that builds on James' strengths and, at the same time, addresses his weaknesses.

Figure 3 shows the evaluation summary the multidisciplinary team used in developing the Accommodation Plan for James. In the first and second columns the summary lists his strengths and weaknesses in academics, behavior, social interactions, and emotional characteristics. Then the problem behaviors are prioritized. The third column indicates ideal outcomes for James. Finally, recommendations are given for additional functional assessment and analysis to pinpoint James's strengths and weaknesses.

Figure 4 presents the Accommodation Plan the team developed, which will be implemented by Ms. Greenbaum, James' third-grade teacher, who is also a member of the team. Several goals are presented to reflect the problem behaviors listed in the evaluation summary. Ms. Greenbaum can delineate more specific objectives after the functional assessments are completed. Then various teaching strategies are recommended that consider the student's strengths. For example, language experience would be a good strategy to improve James's word-recognition skills and to build his spelling vocabulary because it capitalizes on his good verbal skills. Also, positive reinforcement programs likely will be effective given James's need for constant encouragement and attention. Finally, techniques for monitoring James' progress over time are suggested. Ms Greenbaum will make adjustments as she monitors the effectiveness of these approaches. She may be able to enlist the aid of a paraprofessional, student intern, peer tutor, or parent volunteer to work one-on-one with James, particularly for academics.

The multidisciplinary team should meet at least once a year to review James's program, discuss his progress, and make further recommendations. In addition, if James falls farther behind academically, placement in special education may be necessary. By using some of the strategies presented in this article and following the recommendations of the multi- 
disciplinary team, however, the general education program should be able to accommodate James and make learning a successful experience for him.

\section{CONCLUSION}

School districts are mandated to provide services to students with ADHD. As a result, educators must become well informed about the characteristics of students with ADHD, the procedures for identifying and diagnosing ADHD, and the instructional strategies that work best with these students. Given the recent emphases on inclusion of students with special needs in general education classes and multidisciplinary approaches to assessment and instruction, teachers need to work cooperatively with other professionals and parents in designing and delivering educational programs that provide optimal learning experiences for these students. In this way, students with ADHD, will have more opportunity and will be more likely to succeed in school and at home.

\section{REFERENCES}

American Psychiatric Association. (1994). Diagnostic and statistical manual of mental disorders (4th ed.). Washington, DC: Author.

Barkley, R. A. (1990). Attention deficit hyperactivity disorder: A handbook for diagnosis and treatment. New York: Guilford Press.

Barkley, R. A., Fischer. M., Edelbrock. C. S., \& Smallish, L. (1990). The adolescent outcome of hyperactive children diagnosed by research criteria: An 8-year prospective follow-up study. Journal of the American Academy of Child \& Adolescent Psychia$\operatorname{tr}, 29,546-557$

Cameron. J., \& Pierce, W. D. (1994). Reinforcement, reward, and intrinsic motivation: A meta-analysis. Review of Educational Research, 64, 363-423.

Campbell, S. B. (1990). Behavior problems in preschool children. New York: Guilford Press

Campbell, S. A., \& Ewing, L. J. (1990). Follow-up of hard-to-manage preschoolers: Adjustment at age 9 and predictors of continuing symptoms. Journal of Child Psychology \& Psychiatry, 31, $871-889$.

Cessna, K. K., \& Borock, J. (1993). Instructionally differentiated programming: Suggestions for implementation. In K. K. Cessna (Ed.), Instructionally differentiated programming: A needs-based approach for students with behavior disorders (pp. 53-65). Denver: Colorado State Board of Education.

Davila, R. R., Williams, M. L., \& MacDonald, J. T. (1991). Memorandum to chief state school officers re: Clarification of policy to address the needs of children with attention deficit disorders with general and/or special education. Washington, DC: U. S. Department of Education.

DuPaul, G. J. \& Barkley, R. B. (1992). Situational variation of attention problems: Psychometric properties of the revised Home and School Situations Questionnaires. Joumal of Clinical Child Psychology, 21, 178-188.

Dykman, R. A., \& Ackerman, P. T. (1991). Attention deficit disorder and specific reading disability: Separated but often overlapping disorders. Joumal of Learning Disabilities, 24, 96-103.

Foster-Johnson, L., \& Dunlap, G. (1993). Using functional assessment to develop effective, individualized interventions for challenging behaviors. Teaching Exceptional Children, 25, 44-50.

Fowler, M., Barkley, R. A., Reeve, R., \& Zentall, S. (1992). Ch.A.D.D. Educators manual: An indepth look at attention deficit disorders from an educational perspective. Plantation, FL: Ch.A.D.D.

Hallenbeck, B. A., \& Kauffman, J. M. (1995). How does observational learning affect the behavior of students with emotional or behavioral disorders? A review of research. Journal of Special Education, 29, 45-71.

Javorsky, J. (1996). An examination of youth with attentiondeficit/hyperactivity disorder and language learning disabilities: A clinical study. Journal of Learning Disabilities, 29, 247-258.

Lago-Delello, E. (1996). Classroom dynamics and young children identified as at risk for the development of serious emotional disturbance. Unpublished doctoral dissertation. University of Miami.

McKinney, J. D. (1989). Longitudinal research on the behavioral characteristics of children with learning disabilities. Joumal of Learning Disabilities, 22, 141-150.

McKinney, J. D., Montague, M., \& Hocutt, A. (1993). Educational assessment of students with attention deficit disorders. Exceptional Children, 60(2), 125-131.

McKinney, J. D., \& Speece, D. L. (1986). Academic consequences and longitudinal stability of behavioral subtypes of learning disabled children. Journal of Educational Psychology, 78, 365-372.

Montague, M., Bergeron, J., \& Lago-Delello, E. (1997). Using prevention strategies in general education. Focus on Exceptional Children, 29, 1-12.

Osborne, S., Schulte, A. C., \& McKinney, J. D. (1991). A longitudinal study of learning disabled students in mainstream and resource programs. Exceptionality, 2, 81-95.

Swanson, J. M., McBurnett, K., Wigal, T., Pfiffner, L. J., Lerner, M. A., Williams, L., Christian, D. L., Tamm, L., Willcutt, E., Crowley, K., Clevenger, W., Khouzam, N., Woo, C., Crinella, F. M., \& Fisher, T. D. (1993). Effect of stimulant medication on children with attention deficit disorder: A "review of reviews." Exceptional Children, 60, 154-162.

Walker, H. M. (1995). The acting out child: Coping with classroom disruption ( $2 d$ ed.). Longmont, $\mathrm{CO}$ : Sopris West.

Warger, C. L., \& Rutherford, R. B. (1993). Co-teaching to improve social skills. Preventing School Failure, 36, 21-27.

Warger, C. L., \& Rutherford, R. B. (1996). A collaborative approach: Social skills instruction. Ann Arbor, MI: Foundation for Exceptional Innovation 